\title{
THE REVIEW OF LEGISLATIVE INITIATIVES AS REGARDS TAXATION ISSUES IN Q2 2016 ${ }^{1}$
}

\author{
V.Gromov
}

In April-June 2016, lots of proposals on taxation in Russia were developed. The attention was focused on all the main taxes, including the individual income tax, corporate profit tax, property taxes, including the transport tax, the severance tax and the gambling tax. Also, a decision was approved to expand access of small business entities to the simplified scheme of taxation. However, the reform of the system of administration of insurance contributions to the mandatory social insurance should be recognized as one of the most fundamental and large-scale changes.

\section{Direct Taxes on Incomes (Profit)}

1. The details of calculation of the tax amount on incomes in terms of winnings from participation in gambling games and lotteries are specified (1037957-62). It is proposed to formulate Article 214.7 of the RF Tax Code in a new version. At present, it regulates only the specifics of determination of the tax base on incomes in terms of winnings received from a bookmaker's office and pari mutual. The need in changes which were proposed by the RF Government is justified by the fact that the individual income tax in terms of winnings paid by lottery companies and gambling sponsors (except for winnings paid by a bookmaker's office and pari mutual) does not remain at the source of payment, so, it should be calculated and paid by individuals independently on the basis of their tax return (Article 228.1.5 of the RF Tax Code). However, tax control over payment of taxes in such a case cannot be quite effective until tax authorities lack information both on the amount of payment the taxpayer received and the entity which effected that payment. Due to the above, it is proposed to set a responsibility of entities paying out winnings to individuals to calculate, withhold and transfer to the budget the individual income tax as tax agents in cases where the sum of the winnings paid (transferred) is no less than $\mathrm{Rb} 15000$. Within the frameworks of new rules, taxpayers receive advantages as compared to the effective procedure in terms of the right to pay the tax on income in terms of winnings reduced by the value of the bet used as condition for participation in gambling. At present, the tax base includes the total cash amount of the winnings received by the taxpayer. However, the right in question will be available only to persons from whose incomes the tax is withheld. In its turn, for individuals who have received a small amount of winnings from participation in gambling and lotteries a personal exemption of $\mathrm{Rb} 4,000$ will be introduced. In that case, the tax will not be charged at all. In other cases, that is, with incomes ranging from $\mathrm{Rb} 4,000$ to $\mathrm{Rb} 15,000$ the procedure for calculation and payment of the income tax by a taxpayer remains unchanged. In addition to the above, it is planned to set a ban on application of tax deductions provided for by Chapter

1 The Review was prepared on the basis of materials of the official web-site of the State Duma of the Federal Assembly of the Russian Federation (duma.gov.ru).

2 Here and elsewhere the number of a relevant draft law is specified in brackets. 
23 of the RF Tax Code in respect of incomes in terms of winnings received by participants in gambling and lotteries.

2. It is proposed to relieve from taxation individuals' income received from sale of household wastepaper (1039273-6). It is advised to expand the list of incomes which are not subject to the individual income tax (Article 217 of the RF Tax Code) by including in it revenues received by an individual from sale of household wastepaper. At present, about $1 \%$ of the wastepaper is recycled, while the rest which can be processed is buried. The above measure is expected to create both additional tax incentives to engage households in storing up wastepaper and prerequisites to reduce the volume of urban ore, as well as increase wastepaper recycling volumes. In addition to that, it is noted that due to small amounts of incomes they are not declared and the tax is not often paid, while in cases where the tax is declared it is not paid anyway because by size it is smaller than a property tax deduction. However, tax authorities' responsibilities to supervise a tax-collection process are preserved and due to that factor there is growth in administration-related costs. From the RF Government's point of view, the issue in question should be dealt with otherwise as the specifics of payment of the individual income tax are determined by the period within which the property was in the individual's ownership, while determination of such a period in respect of wastepaper and wastepaper purchase-related expenses is an inadministrable task. So, tax withholding at the source of payment of income with partial tax exemption is regarded the optimal option.

3. It is proposed to exempt from the individual income tax rewarding incentives to athletes, coaches and other experts in the field of physical culture and sports (1089267-6). The above initiative is already implemented in Article 217.20.1 of the RF Tax $\operatorname{Code}^{1}$ and is aimed at promotion of the Olympic movement in Russia and achievements of outstanding sportsmen who win prizes at the Olympic, Paralympic and Deaflympics Games, as well as coaches and other experts who participated directly in training of those athletes. The benefit represents an exemption from taxation of lump sum payments of additional rewarding incentives in cash and/ or in kind received from non-profit institutions whose charter purpose of the activities is organizational and financial support of projects and programs in the field of sport high achievements. So, the tax benefit is granted to individuals who made an important contribution to development of physical culture and sports in the Russian Federation.

4. It is proposed to tax material benefits from saving on interests in utilizing borrowed (credit) funds only in cases where entities and individual entrepreneurs which extended a loan are related parties in respect of the taxpayer (1098704-6). In other words, it is proposed to charge the tax on the same terms - as in case of related parties - which are applied in respect of transactions on purchasing of goods (jobs and services). At present, the material benefit is regarded received whenever there is saving on interests on loans. In substantiation of changes, it is stated that charging of the tax is unjustified in cases where such a saving is formal and is in no way related to the purposes of artificial reduction of the tax. Proceeding from the above, the material benefit in such a situation should not be recognized as the individual's

1 Federal Law No.247-FZ of 3 July 2016 on Amendment of Article 217 of Part 2 of the Tax Code of the Russian Federation. 
income and result in additional financial burdens which factor is particularly important with the current economic situation taken into account.

5. It is proposed to increase the amount and expand the area of application of a social tax deduction in respect of education expenditures (1106041-6). The above initiative actually includes the following three measures:

1) to raise twofold the ultimate amount of a social tax deduction in respect of expenditures on education of a child; according to Article 219.1.2 of the RF Tax Code the taxpayer is in a position to reduce income by the amount of actual expenditures related to education of his/her child within the limits of $\mathrm{Rb} 50,000$ per child in the total sum stipulated for both the parents. In the draft law, it is proposed to raise the ultimate amount of deduction to $\mathrm{Rb} 100,000$ proceeding from the fact that in current conditions the cost of education is much higher ( $2-3$ times), so the existing maximum amount of deduction is irrelevant;

2) to raise the amount of the aggregate limitation on social deductions to $\mathrm{Rb} 200,000$ which factor permits to accept for deduction a larger amount of expenditures on personal education; in Article 219.2 of the RF Tax Code it is set at present at the level of $\mathrm{Rb} 120,000$ for a fiscal period;

3 ) to set a deduction in the amount of the taxpayer's expenditures on rentals in cases where a student is not provided with accommodation at a student hostel or there is a lack of such accommodation within the following limits: the total sum of the limitation on social deductions in case of payment for one's own education or $\mathrm{Rb} 200,000$ per each child in the total amount for both the parents in case of payment for education of their children.

6. It is advised to cancel a special depreciation allowance in the amount of $30 \%$ by virtue of the fact that such an opportunity granted to taxpayers results in growing shortfall in budget revenues of constituent entities of the Russian Federation (1043832-6).

7. It is proposed to change the procedure for carrying forward balances of property tax deductions (for acquisition/building of housing and redemption of interests on housing loans) to the previous fiscal periods. The above procedure is meant for pensioners (1108212-6). According to Article 220.10 of the RF Tax Code, carrying forward of the balances of tax deductions is carried out within the limits of three years preceding directly the fiscal period in which carrying forward of tax deduction balances took place. It is stated that the disadvantage of the above norm consists in the fact that it cannot actually be used when after retirement of the taxpayer and purchasing by him/ her of a real property more than three years have passed: in receiving the pension alone there are no previous periods' taxable incomes which could be reduced by the sum of the deduction. It is to be noted that even if less than three years have passed it is highly unlikely that a complete tax deduction can be secured. So, it is proposed to carry forward the unutilized sum of a tax deduction to the past within the limits of three years prior to a fiscal period in which the taxpayer started to receive the pension, that is, the period when the taxpayer had a taxable income each year for three years.

\section{Indirect Taxes}

8. The guidelines for distribution of excises on petrochemicals between the federal budget and budgets of constituent entities of the Russian Federation were specified (1040490-6). It is proposed to transfer a portion of revenues from excises on motor petrol, directly distilled gasoline, diesel fuel and 
engine oil for diesel and/or carburetor (injector) engines produced in the Russian Federation to the federal budget: from 1 June 2016 tax revenues from payment of those excises in the amount of $12 \%$ are transferred to the federal budget, while regional budgets receive the remaining $88 \%$ instead of the previous $100 \%$. Before that date, those payments in full were credited to regional budgets and nothing was paid to the federal budget. Amendments were approved for the purpose of securing a balanced replenishment of the Federal Road Fund and road funds of constituent entities of the Russian Federation with taking into account growth in budget revenues related to higher rates of excises on petrochemicals from 1 April 2016. It is noteworthy that the above initiative has already been implemented and a relevant law was approved ${ }^{1}$.

9. It is proposed to exempt from the value added tax (VAT) operations related to import to the territory of the Russian Federation and other territories under its jurisdiction cultural valuables bought by or donated to nonstate museums (1074400-6). According to Article 150.4 of the RF Tax Code, at present the tax benefit is available only to state and municipal institutions of culture. The initiative is substantiated by the fact that at present it is necessary to create conditions for development of the Russian art-market and establishment of non-government museums. So, for that purpose it is important to ensure both free disposal of cultural valuables bought abroad and repatriation of those that were earlier taken out from the RF. According to the concept of the architects of the draft law, implementation of that measure will promote international cultural cooperation and contribute to replenishment of holdings of museums and development of private collections.

\section{Property Taxes}

10. It is proposed to set the rate of the land tax in the amount of $0 \%$ if land plots attributed to land of agricultural designation or land inside the area of agricultural utilization in settlements have been used for agricultural production within three or more years (1042595-6); the above measure is meant to motivate utilization of such lands in conformity with designated purpose.

11. It is proposed to change the procedure for accounting of cadastral cost of the tax base (1055202-6) as regards the corporate property tax, land tax and individual property tax in respect of which the tax base is determined as a cadastral cost as of 1 January of the year which is the fiscal period. It is proposed to envisage in the tax legislation an option to adjust backdated the value of the cadastral cost if that cost was erroneously determined and by decision of the commission on resolution of cadastral cost related disputes or a court is subject to change, but was used for calculation of the tax which the taxpayer is to pay on the basis of the results of the previous fiscal period. The above initiative was substantiated by numerous litigations over errors made during mass appraisals of the tax base where cadastral cost surpassed greatly the actual market cost. According to the effective rules, calculation of the tax after the cadastral cost was adjusted is feasible only from the year in which an application for adjustment was submitted (Article 378.2.15 of the RF Tax

1 Federal Law No.145-FZ of 23 May 2016 On Amendment of the Budget Code of the Russian Federation and Article 6 of the Federal Law on Amendment of the Budget Code of the Russian Federation and Article 50 and Article 30 of the Federal Law on Amendment of Individual Statutory Acts of the Russian Federation to Upgrade the Legal Status of State (Municipal) Entities. 
Code, Article 391.1.6 of the RF Tax Code and Article 403.2 of the RF Tax Code). In other words, the unjustified excess amount of the tax paid for the previous year is not subject to change even if the claims for adjustment were met. This situation makes property taxation unfair. Proceeding from the above, to make it possible for the taxpayer to pay the tax on the basis of the actual and not overstated value of the taxable property unit the correct cadastral value should be applied not from the new fiscal period when the tax liability cannot be specified and adjusted, but from the previous fiscal period in respect of which the erroneous cadastral duty was actually used for calculation of the tax. It is admissible as a retroactive force of the draft law's norms which by the concept of the architects of the draft law were to be effective in respect of legal relations arising from 1 January 2015 does not make the situation of taxpayers worse. The RF Government does not support that initiative justifying its position by the fact that the outputs of the state cadastral appraisal are used in budget planning which in case of approval of the proposed measures becomes infeasible.

12. It is proposed to cut the corporate property tax rate in respect of railway tracks of general use, as well as facilities which are an integral technological part thereof (1074366-6). Article 380.3 of the RF Tax Code provides for gradual growth in the tax rate on such a property: in 2016 it is to amount maximum to $1.3 \%$ while in 2017 and 2018, to $1.6 \%$ and $1.9 \%$, respectively. In its turn, the RF Government which prepared the draft law to motivate development and modernization of the general use railway transport infrastructure proposed to reduce the rate's upper margin set for 2016 to $1 \%$, while in cases where from 1 January 2016 such facilities were accounted for as capital assets, to apply the tax rate of $0 \%$ in the 2017 fiscal period, as well. However, according to the RF Audit Chamber the above proposal is in conflict with the earlier approved and legislatively implemented course to gradually abolish federal benefits set in respect of regional and local taxes, including privileges in respect of infrastructure facilities, taking into account the fact that both target indicators and the criteria of assessment of efficiency of tax privileges are not determined.

13. It is proposed to set a transport tax privilege in the amount of the fee in lieu of indemnification of damage caused to general use motor roads of federal status by transport vehicles with permitted gross laden weight of over 12 tons (1053039-6). Proceeding from the fact that concurrent payment of the transport tax and the above fee resulted in excessive growth in a tax burden, it was decided to relieve owners of overweight vehicles (both individuals and legal entities) from payment of the transport tax in cases where the amount of the fee for them was higher or equal to the amount of the transport tax in the fiscal period. In cases where the transport tax is higher, the tax privilege is in the form of a tax deduction from the amount of payment. Accordingly, the remaining portion of the transport tax is to be paid. As the issue in question is particularly urgent, the initiative has already been implemented in provisions of the RF Tax Code ${ }^{1}$. It is expected that the procedure in question is temporary and the transition period is over until 2019.

14. It is proposed to cancel the transport tax (1094376-6). According to the explanatory note to the draft law, taxation of car owners is to be carried

1 Federal Law No. 249-FZ of 3 July 2016 on Amendment of Part 2 of the Tax Code of the Russian Federation. 
out on the basis of the "drive more, pay more" principle which should be implemented by way of shifting of the tax burden in favor of excises included in prices paid by car owners when they buy gasoline. It is to be noted that growth in excises which actually took place does not meet those goals. According to the stance of the RF Audit Chamber, it is inexpedient to approve the above initiative as it may result in a substantial reduction (minimum $\mathrm{Rb}$ $140 \mathrm{bn}$ ) of local budget revenues as the tax in question is transferred in full to constituent entities of the Russian Federation. In addition to the above, it is noted that alternative sources of compensation for such losses are not determined. It is noteworthy that the initiative in question, that is, to exclude Chapter 28 of the RF Tax Code - was put forward twice in the period under review, including draft law No. 1072817-6.

\section{State Duties}

15. It is proposed to exempt from payment of a state duty for notarial actions heirs of RF National Guard servicemen (1037372-6). The above measure was proposed by the RF President in connection with establishment of the Federal National Guard Service as a successor of the RF Interior Ministry troops ${ }^{1}$.

16. It is proposed to set a state duty in the amount of $\mathrm{Rb} 65,000$ (1038599-6) for issuing of licenses to production, storage, supply and/or retail sale of wine produced by farming enterprises and individual entrepreneurs recognized as agricultural goods producers (Article 333.33 of the RF Tax Code). The above measure was proposed to underpin small and mid-sized businesses of the wine industry and promote competition on the market of alcohol products ${ }^{2}$.

17. It is proposed to relieve from payment of the state duty individuals who are entitled to free legal aid within the frameworks of the state free legal aid system in hearing of cases in which the interests of those persons are represented by a state judicial office or lawyers (1042654-6).

18. It is proposed to relieve from payment of a state duty non-state museums for the right to take temporary out of the country cultural valuables which are in their permanent storage (1074400-6), as well as set the duty rate in the amount of $5 \%$ of the value in respect of cultural valuables created less than 100 years ago (at present as per Article 333.33.1.34 of the RF Tax Code such a duty rate is applied if cultural valuables were created 50 years ago or even more).

19. It is proposed to calculate the size of a state duty in receiving by individuals of state and municipal services in an electronic format with the ratio of 0.7 without a condition that the output of the service is provided in an electronic format (1091253-6). At present, payment of a reduced duty is admissible if the taxpayer not only applies for, but also receives service at the web-site of state and municipal services (Article 333.35.4 of the RF Tax Code). However, one can receive, for example, a marriage certificate or passport only personally, so the size of the duty cannot be reduced even if the service was applied for through the internet. It is the above factor that makes the benefit not very popular, but the measure in question is expected to increase the number of electronic applications by individuals and, thus, reduce expenses related to reception of visitors and processing of applications.

1 The initiative supported: Federal Law No.228-FZ of 3 July 2016 on Amendment of Article 333.38 of Part 2 of the Tax Code of the Russian Federation.

2 The initiative supported: Federal Law No. 245-FZ of 3 July 2016 on Amendment of Article 333.33 of Part 2 of the Tax Code of the Russian Federation. 


\section{Severance Tax}

20. It is proposed to change the tax base in respect of generally used minerals: natural mortar sand (1034185-6) using instead of the cost the volume of produced minerals in physical terms. At present, as per Article 338 of the RF Tax Code the volume of produced minerals is used for tax calculation purposes in production of coal and crude hydrocarbons, while in case of other minerals, their cost. According to the architects of the draft law, in most cases that cost is several dozens of times lower than the average cash-in value of minerals due to which factor there are imbalances between the tax base and the actual cost of the produced minerals. To eliminate them, it is proposed to charge the tax at a fixed rate of $\mathrm{Rb} 30$ per a cubic meter of produced natural mortar sand. In the findings of the RF Audit Chamber, it is pointed out that the above measure actually has growth potential for budget revenues, however, the size of the rate is not quite substantiated as in case of taxation on the basis of volume the scheme of tax rate adjustment ratios specific to particular production is utilized, but such a scheme was not proposed and that factor can create unequal taxation conditions for companies with different cost-effectiveness of production.

21. It is proposed to change the norms of paying the severance tax as regards crude hydrocarbons, with transferring $15 \%$ of the relevant tax revenues to the budget of a constituent entity of the Russian Federation and 85\% to the federal budget (1066720-6). At present, as per Article 50 of the RF Tax Code those tax revenues are paid in full to the federal budget. A similar initiative, but with an alternative option of implementation is proposed in another draft law (1075849-6) under which those revenues are to be paid in full to the regional budget, but only in case if their share in total budget revenues of a constituent entity of the Russian Federation amounts at least to $30 \%$.

\section{Gambling Tax}

22. It is proposed to single out as independent taxable units processing centers of bookmaker's offices and pari mutuals, which carry out accounting of interactive bets (1037957-6). Proceeding from the fact that due to acceptance of interactive bets there is growth in profitability of sponsors of gambling, it is proposed to set a tax rate within the range of $\mathrm{Rb} 2.5 \mathrm{~m}$ to $\mathrm{Rb} 3 \mathrm{~m}$ in respect of each taxable unit.

\section{Special Tax Regimes}

23. It is proposed to increase twofold the ultimate value of the income size which permits a switchover to a simplified scheme of taxation (SST) from $\mathrm{Rb} 45 \mathrm{~m}$ to $\mathrm{Rb} 90 \mathrm{~m}$, as well as the value of income - which if surpassed makes a switchover to the simplified taxation scheme impossible - from $\mathrm{Rb} 60 \mathrm{~m}$ to $\mathrm{Rb} 120 \mathrm{~m}$. Along with that, capital assets' depreciation value will be increased from $\mathrm{Rb} 100 \mathrm{~m}$ to $\mathrm{Rb} 150 \mathrm{~m}$ and if surpassed application of the simplified scheme of taxation is prohibited (1040802-6). The above proposals are included in the future wording of Chapter 26.2 of the RF Tax Code which become effective from 1 January 2017.

\section{Administration}

24. It is proposed to assign tax authorities with powers to carry out administration of insurance contributions to the system of mandatory pension, social and medical insurance (1040802-6). The above initiative of the 
RF Government is justified by the long-standing need to upgrade the quality of administration of mandatory deductions for social needs; in 2010 those deductions were transformed from the single tax into insurance contributions. After the reform was carried out, debates on whether it was rationale continued mostly due to the fact that those payments were essentially similar to taxes; also the issue whether tax authorities were more efficient as the administrator of state revenues was discussed. The proposed changes represent not only amendments to the legislation, but also they are virtually related to the reform of the scheme of mandatory payments. In the explanatory note to the draft law, it is stated that changes are aimed at consolidation of payment discipline in carrying out of settlements with the Pension Fund of the Russian Federation, the Social Insurance Fund of the Russian Federation and the Federal Mandatory Medical Insurance Fund and upgrading of the procedure for calculation and payment (transfer) of insurance contributions to the above institutions. The specifics of the 2016 reform consists in the fact that assignment of such powers in respect of contributions is carried out without recognition of the tax nature of social payments, so they still retain their former name. However, they are transferred into the field of regulation of tax relations and will be a part of the tax legislation. It is important that administration of social payments is no longer dependent on solution of the issue of their legal nature and the emphasis is shifted in favor of efficiency of collection and convenience of payment. Control over payment of contributions will be carried out by the Federal Tax Service. In development of the above initiative, the case for the procedure in question was taken into account. It included establishment of the unified legal base in the system of mandatory payments (taxes and insurance contributions), simplification of that system and formation of unbiased data on the tax burden, reduction of administrative burden on business through bringing to the minimum of the number of supervising entities and inspections and optimization of the content of supplied reporting, upgrading of the quality of compliance measures and unification of rules of administration. The tax legislation will regulate issues of payment of not only taxes and duties, but also insurance contributions, except for insurance contributions to the mandatory social insurance against industrial accidents and occupational diseases and the mandatory medical insurance of non-working population. It is expected to introduce new Chapter 2.1 "Insurance Contributions in the Russian Federation" to Part 1 of the Tax Code. In accordance with the above chapter, insurance contributions will be recognized as federal payments which are subject to payment in the entire territory of the Russian Federation. In Part 2 of the RF Tax Code, new Section XI "Insurance Contributions in the Russian Federation" will deal with insurance contributions. The new amendments will become effective from 1 January 2017: such a procedure is secured by Federal Law No.243FZ of 3 July 2016 on Amendment of Part 1 and Part 2 of the Tax Code of the Russian Federation in Connection with Assignment to Tax Authorities of Powers to Carry Out Administration of Insurance Contributions to the Mandatory Pension, Social and Medical Insurance ${ }^{1}$. In other words, the draft law is approved.

1 By the same Law, amendments are introduced into the procedure for simplification of the scheme of taxation. 